\title{
PENENTUAN OOIP BERDASARKAN PEMODELAN GEOLOGI DAN RESERVOIR DI DAERAH TANISHA CEKUNGAN SUMATRA SELATAN
}

\author{
Nila Rahayu ${ }^{1)}$, Ratnayu Sitaresmi ${ }^{2}$, Moeh. Ali Jambak ${ }^{3)}$. \\ ${ }^{1,2,3)}$ Program Studi Magister Teknik Perminyakan Universitas Trisakti \\ Corresponding author, email : nilarahayu90@gmail.com
}

\begin{abstract}
Abstrak
Perkembangan teknologi dapat dimanfaatkan untuk mengetahui karakteristik reservoir sebelum dilakukannya kegiatan eksplorasi dan eksploitasi. Salah satunya dengan pemodelan geologi dan pemodelan reservoir untuk mendapatkan gambaran bentuk bawah permukaan, karakteristik reservoir, dan OOIP. Analisis data log dan interpretasi geologi dilakukan untuk mendapatkan informasi lingkungan pengendapan, marker lapisan, dan bentukan struktur reservoir yang digunakan sebagai dasar pembuatan model geologi. Analisis petrofisik akan memberikan informasi mengenai karakteristik batuan reservoir. Untuk mendapatkan model reservoir, hasil analisis petrofisik akan didistribusikan pada model geologi. Kemudian penentuan OOIP dapat dihitung dengan menggunakan metode volumetrik.

Reservoir batupasir sudah terbukti menjadi reservoir produktif di berbagai lapangan migas, seperti reservoir batupasir pada Formasi Talang Akar di Lapangan Sungai Lilin. Terdapat enam lapisan yang menjadi obyek penelitian pada Formasi Talang Akar yaitu lapisan D1, D2, E1, E2, F, dan H yang diendapkan pada lingkungan delta plain-delta front terlihat dari pola log yang berkembang yaitu funnel shape, serrated shape, dan bell shape. Perbedaan lingkungan pengendapan akan mempengaruhi geometri dan karakteristik reservoir. Didapatkan nilai cut-off untuk $\mathrm{Vcl} \leq 0.40$, porositas $\geq 0.10$ dan saturasi air $\leq 0.7$. Hasil analisis petrofisika kemudian didistribusikan pada model geologi dengan metode Sequential Gaussian Simulation, dimana penyebaran lingkungan pengendapan menjadi arahan dasar penyebaran properti reservoir. Perhitungan OOIP pada enam lapisan di Formasi Talang Akar berdasarkan pemodelan reservoir sebesar 8,387 MSTB, dengan lapisan menarik terdapat pada lapisan E2 2,340 MSTB.
\end{abstract}

Kata kunci: Pemodelan Geologi, Pemodelan Reservoir, Perhitungan Cadangan, Petrofisika, Model Statik

\section{Pendahuluan}

Batupasir sudah terbukti menjadi reservoir produktif di berbagai lapangan migas, salah satunya adalah Lapangan Tanisha yang mempunyai reservoir berupa batupasir dari Formasi Talang Akar. Terdapat 32 sumur yang telah dilakukan pemboran dengan jarak antar sumur adalah $\pm 300 \mathrm{~m}$. Penelitian ini diharapkan dapat memberikan gambaran bentuk bawah permukaan, karakteristik reservoir, dan OOIP pada Lapangan Tanisha dari Formasi Talang Akar.
Dalam penelitian ini, permasalahan yang dibahas adalah mengenai model bawah permukaan reservoir, OOIP dan zona menarik di Formasi Talang akar.

Lapangan Tanisha secara regional terdapat di Cekungan Sumatra Selatan dengan SubCekungan Palembang Utara terlihat pada Gambar 1. Target utama pada Formasi Talang Akar yang diendapkan pada lingkungan deltaik pada umur Oligosen Akhir - Miosen Awal dengan fase tektonik ekstensional relatif tenang ditunjukkan pada Gambar 2. 


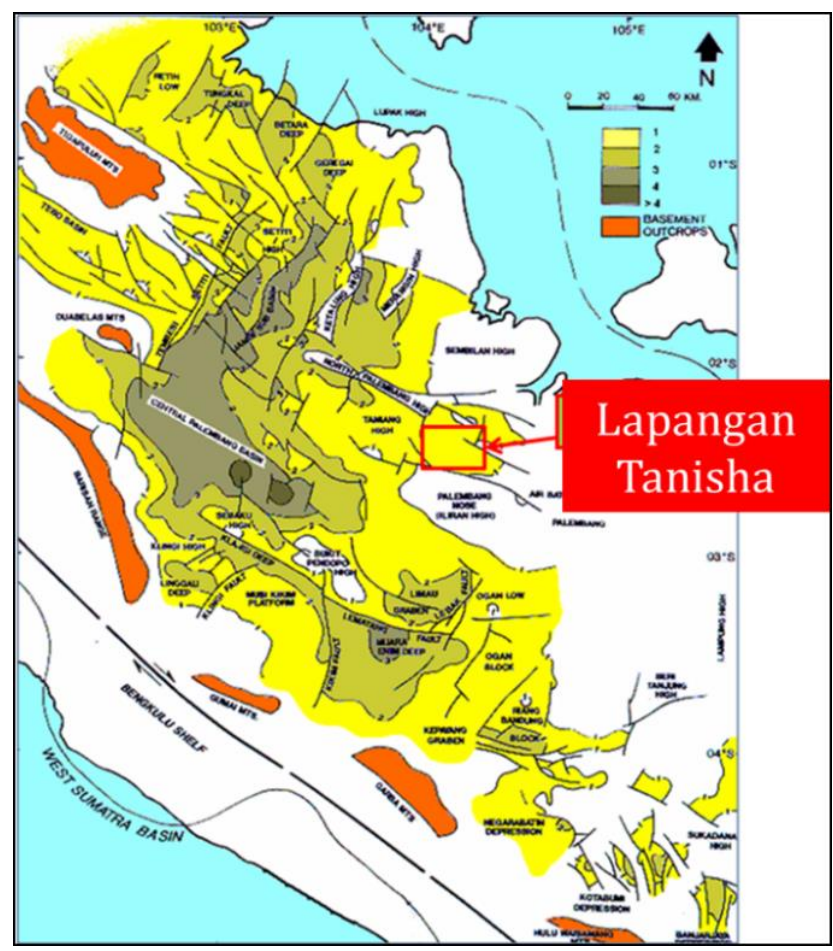

Gambar 1.Lokasi Lapangan Tanisha di Cekungan Sumatra Selatan (Pertamina BEICIP FRANLAB, 1992).

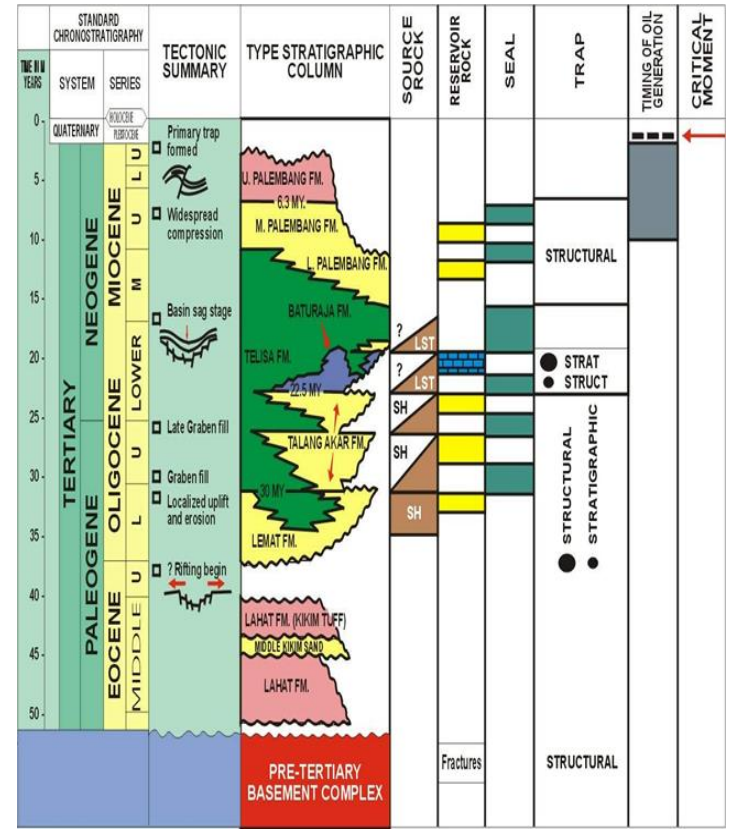

Gambar 2. Stratigrafi Regional Cekungan Sumatra Selatan (dimodifikasi dari Bishop, 2001) 


\section{Metodologi}

Secara umum, terdapat empat tahapan proses dalam menghitung $O O I P$, yaitu analisis petrofisika, pemodelan geologi, pemodelan reservoir, dan perhitungan $O O I P$.

a. Analisis Petrofisika

Analisis petrofisika dilakukan untuk menentukan properti dengan menganalisa $\mathrm{Vcl}$, porositas, dan saturasi air. Analisis $\mathrm{Vcl}$ digunakan untuk menghitung lapisan yang mempunyai sisipan berupa shale/serpih yang dapat mempengaruhi hasil analisis porositas dan saturasi air dengan menggunakan persamaan:

$V s h=\frac{(\text { GR read }- \text { GR min })}{(\text { GR } \text { max }- \text { GR min })}$

dimana $\mathrm{Vcl}$ adalah Volume clay (\%).

Analisis porositas dalam penelitian ini divalidasi dengan data core berdasarkan log neutron menggunakan persamaan:

$\emptyset N=\emptyset n-(\emptyset n s h \times V s h)$

dimana $\emptyset \mathrm{N}$ adalah porositas neutron (\%).

Perhitungan saturasi air untuk mengetahui volume fluida yang mengisi pori batuan terhadap volume total pori-pori batuan menggunakan persamaan Indonesia karena memperhitungkan kandungan air dalam perselingan antara batuserpih dan batupasir (Fertl dan Hammack, 1971).

$\mathrm{SW}=\left[\frac{\frac{1}{R t^{0.5}}}{\frac{V s h l^{1-V s h l / 2}}{R s h^{0.5}}+\frac{\emptyset^{m / 2}}{(a * R w)^{0.5}}}\right]$

dimana $S w$ adalah saturasi air (\%).

b. Pemodelan Geologi \& Reservoir

Dalam proses pembuatan model geologi \& reservoir terdiri dari beberapa tahapan, yaitu: (1) pengumpulan data primer berupa data log, seismik 2D dan data core; data pustaka sebagai referensi, untuk membuat analisis awal sehingga mengetahui konsep kerja yang akan dilakukan selanjutnya seperti mengetahui konsep-konsep geologi yang menjadi dasar pembuatan model; (2) Pemodelan struktur, melakukan analisis log dan interpretasi seismik dengan menentukan marker tiap lapisan dan patahan dengan mempertimbangkan aspek geologi. Hasil analisis tersebut kemudian diproses menjadi model 3D; (3) pembuatan grid 3D yang memiliki tiga sumbu $\mathrm{X}, \mathrm{Y}$, dan $\mathrm{Z}$ yang terdiri dari sel-sel untuk menyebarkan properti reservoir. Dalam proses ini dilakukan penentuan zona dan horizon sebagai permukaan lapisan serta memasukkan dan mendistribusikan data log sumur ke dalam grid beserta koreksinya (scale up); (4) pemodelan Litologi, proses ini dilakukan dalam pemodelan fasies dengan pendekatan lingkungan pengendapan. Terdapat dua metode yang dapat digunakan yaitu metode stokastik dan deterministic; (5) pemodelan petrofisika, pembuatan model properti reservoir secara kuantitatif dan kualitatif yang didasarkan dan dikoreksi oleh model fasies dengan mempertimbangkan data sumur, variogram, dan trend. Dalam pemodelan porositas menggunakan trend model fasies, dan pemodelan saturasi air menggunakan trend model porositas.

c. Perhitungan $O O I P$

Terdapat dua metode utama dalam metode volumetrik perhitungan OOIP yaitu metode deterministik dan probabilistik. Penelitian ini berfokus pada metode deterministik, dimana metode ini memeratakan data-data dari titik- titik pada reservoir, dari data log sumur, inti batuan (core), dan seismik untuk menghitung luasan persebaran properti di lapangan.

$S T O I I P=\frac{G R V \cdot \frac{N}{G} \cdot \emptyset \cdot S o}{B o}$.

dimana STOIIP adalah jumlah cadangan awal minyak $(S T B)$.

\section{Hasil Dan Pembahasan}

Tahap pertama yang dilakukan pada pengerjaan penelitian ini adalah analisis marker sumur. Penentuan tersebut didapat dari analisis GR, referensi hasil laporan sumur dan juga didasarkan pada kesamaan karakter reservoir dan melanjutkan analisis yang sudah dilakukan sebelumnya. Dari analisis tersebut didapatkan tujuh lapisan yaitu D1, D2, E1, E2, F, G, dan H, dimana lapisan G tidak dijadikan target utama karena merupakan lapisan batubara ditunjukkan pada Gambar 3 . 


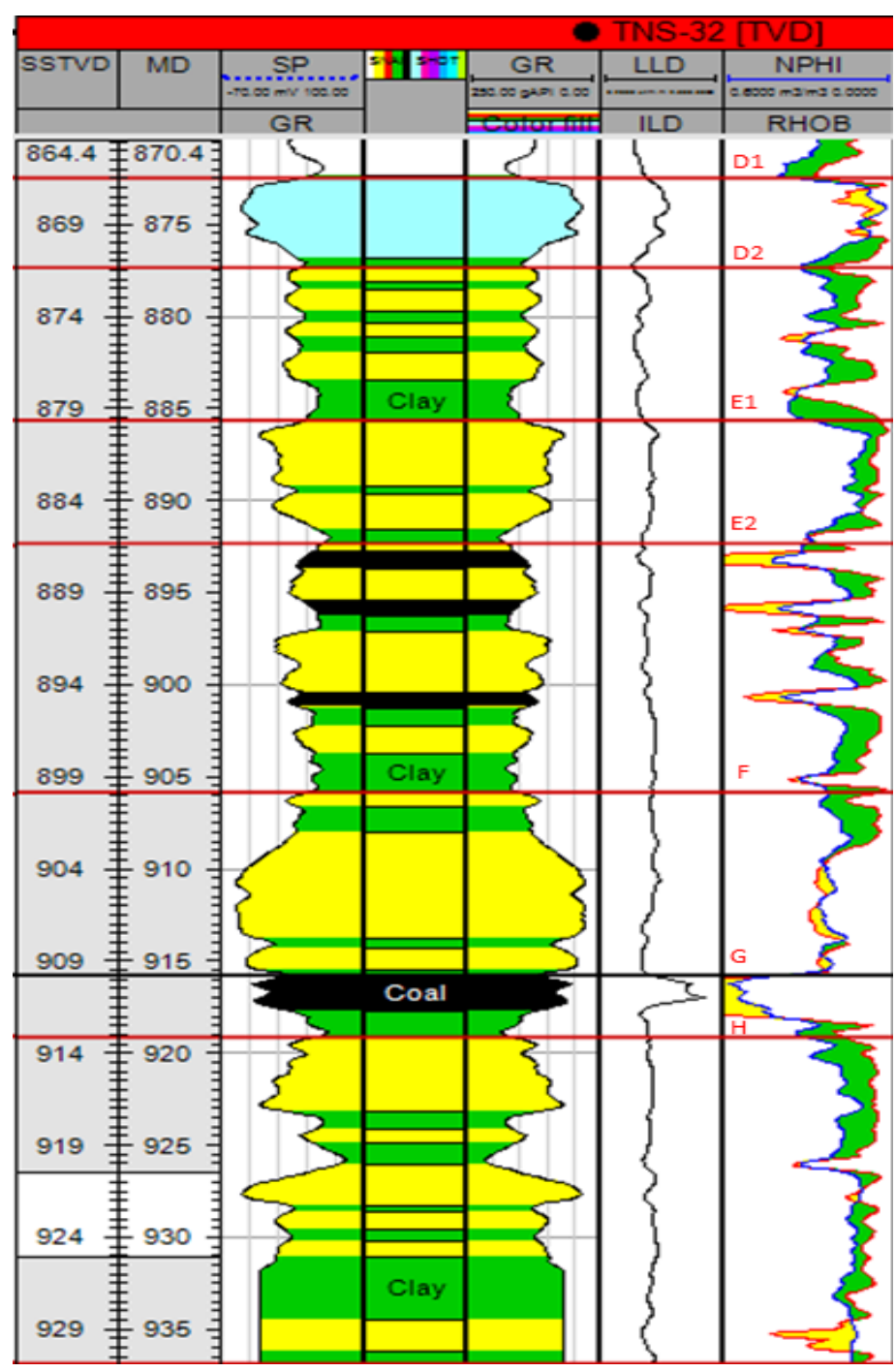

Gambar 3 Analisis marker Top \& Bottom lapisan pada sumur TNS-032 (KSO Pertamina, 2013)

Pada Lapangan Tanisha terdapat tiga dominan tipe log yaitu funnel shape, serrated shape dan bell shape yang menunjukkan daerah ini diendapkan pada di lingkungan distribution channel, delta plain, mouth bar, dan delta front Gambar 4. Dalam analisis petrofisik diperlukan perhitungan volume shale yang dapat mempengaruhi produktifitas suatu lapisan. Salah satu metode untuk menghitung volume shale menggunakan pengukuran log sinar gamma ray. Hasil estimasi volume shale untuk studi ini ditunjukkan pada Gambar 5. Analisis porositas sudah divalidasi dengan data core, perhitungan porositas yang mendekati dengan data core menggunakan metode perhitungan porositas neutron. Analisis saturasi air dilakukan menggunakan Indonesia Equation yang dibuat pada litologi shaly sand di Indonesia, hal ini dikarenakan sangat tingginya kandungan shale yang terdapat di area Indonesia (Worthington 1985).

Hasil analisa porositas dan saturasi air ditunjukkan pada Gambar 6.Didapatkan Cut-off Vcl sebesar 0.4 , porositas 0.1 dan $S W 0.7$. 


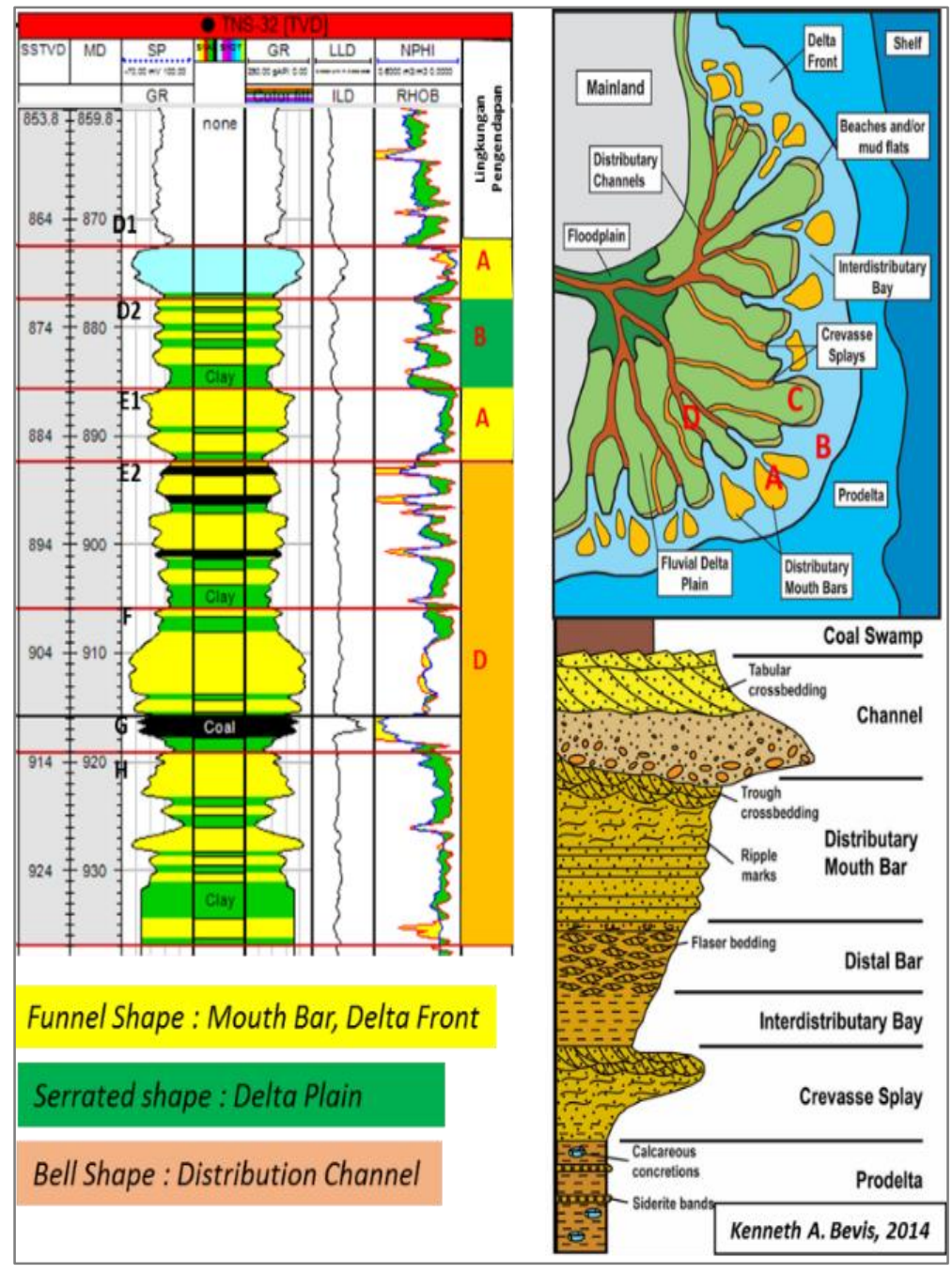

Gambar 4 Daerah Lingkungan Pengendapan Lapangan Tanisha Di Delta Plain-Delta Front Berdasarkan Klasifikasi (Kenneth A. Bevis, 2014) 


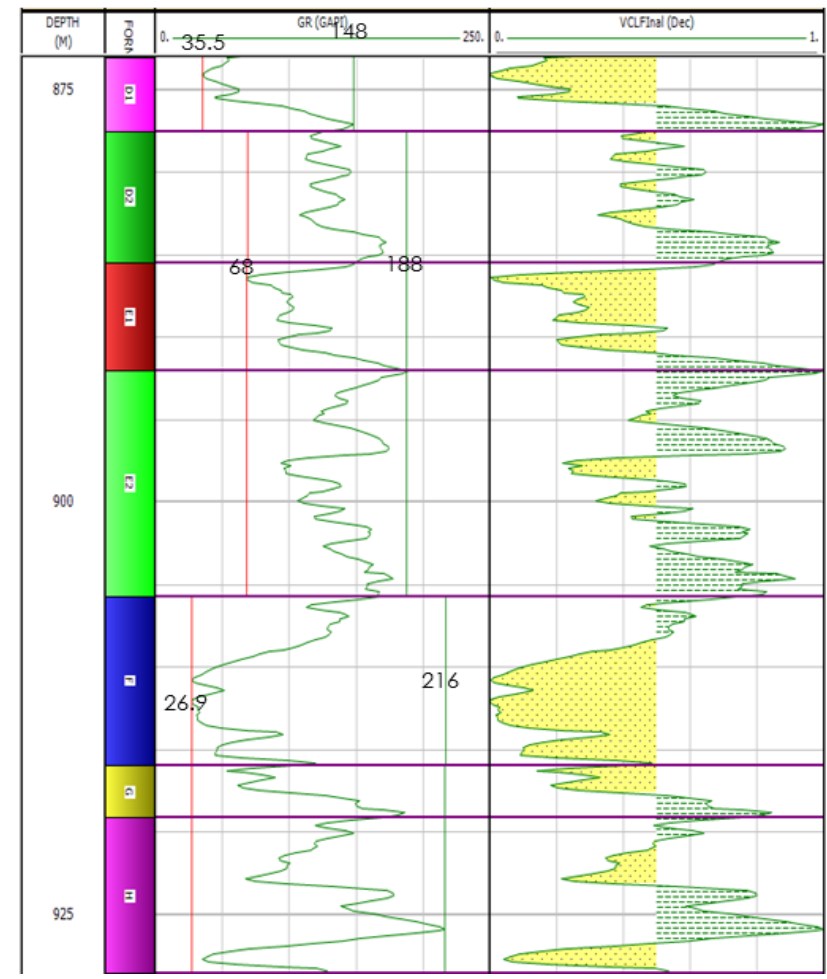

Gambar 5 Analisis Vsh pada Sumur TNS-032 dengan Mengidentifikasikan Nilai GRmax dan GRmin Mempengaruhi Analisis Porositas dan Saturasi Air

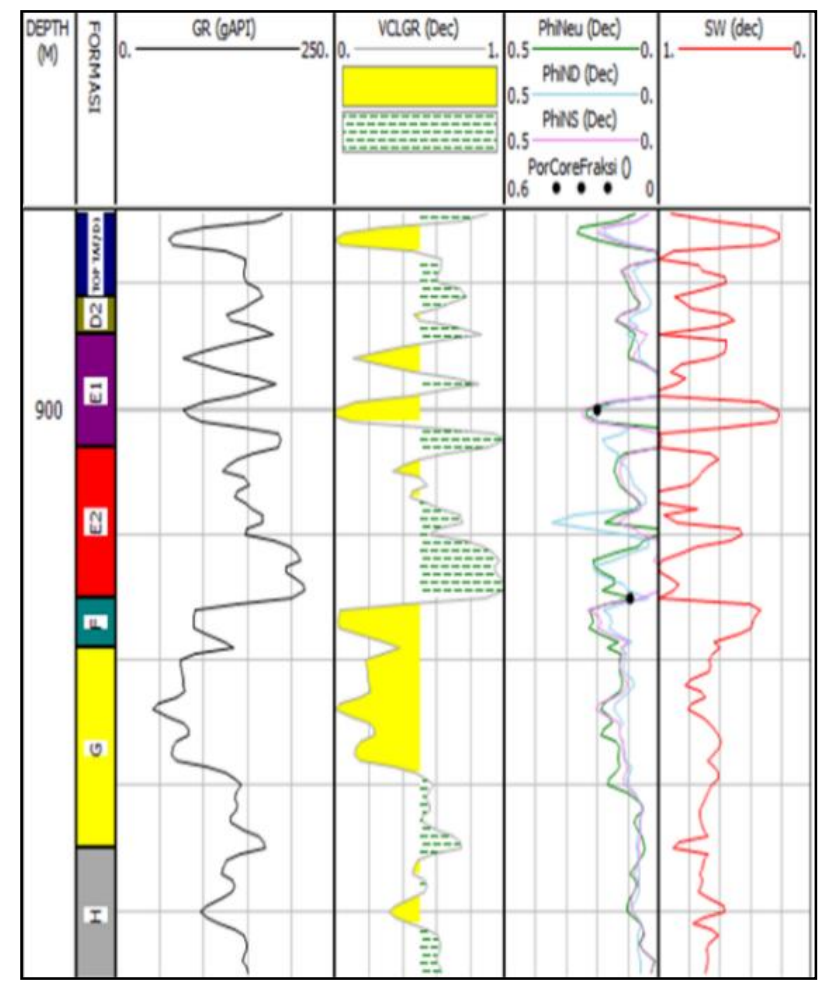

Gambar 6. Perbandingan Perhitungan Porositas yang sudah Divalidasi dengan Data Core, Metode Porositas Neutron dapat digunakan dalam Analisis dan Hasil Perhitungan Saturasi Air dengan Menggunakan Indonesia Equation pada Sumur ADR-043 karena Mempertimbangkan Kehadiran Shale. 
Proses pemodelan struktural diawali dengan membuat model patahan hasil dari interpretasi seismik yang kemudian dilanjutkan dengan pembuatan pillar gridding $3 D$ yang terdiri dari sel-sel pada bagian atas, tengah, dan bawah. Pillar gridding ini akan menjadi dasar penyebaran properti. Kemudian pembuatan horizon modeling hasil dari interpretasi lapisan di seismik. Tahapan selanjutnya dengan pembuatan zonasi dengan input well marker dari analisis log. Proses terakhir yaitu layering model, ketebalan layer ini akan dipengaruhi oleh ketebalan litologi (Gambar 7). Ukuran grid dalam pemodelan geologi $20 \mathrm{mx} 20 \mathrm{~m}$ dengan total sell 8.709.732 dan total layers 73 . Ketebalan rata-rata per layer adalah $1 \mathrm{~m}$.

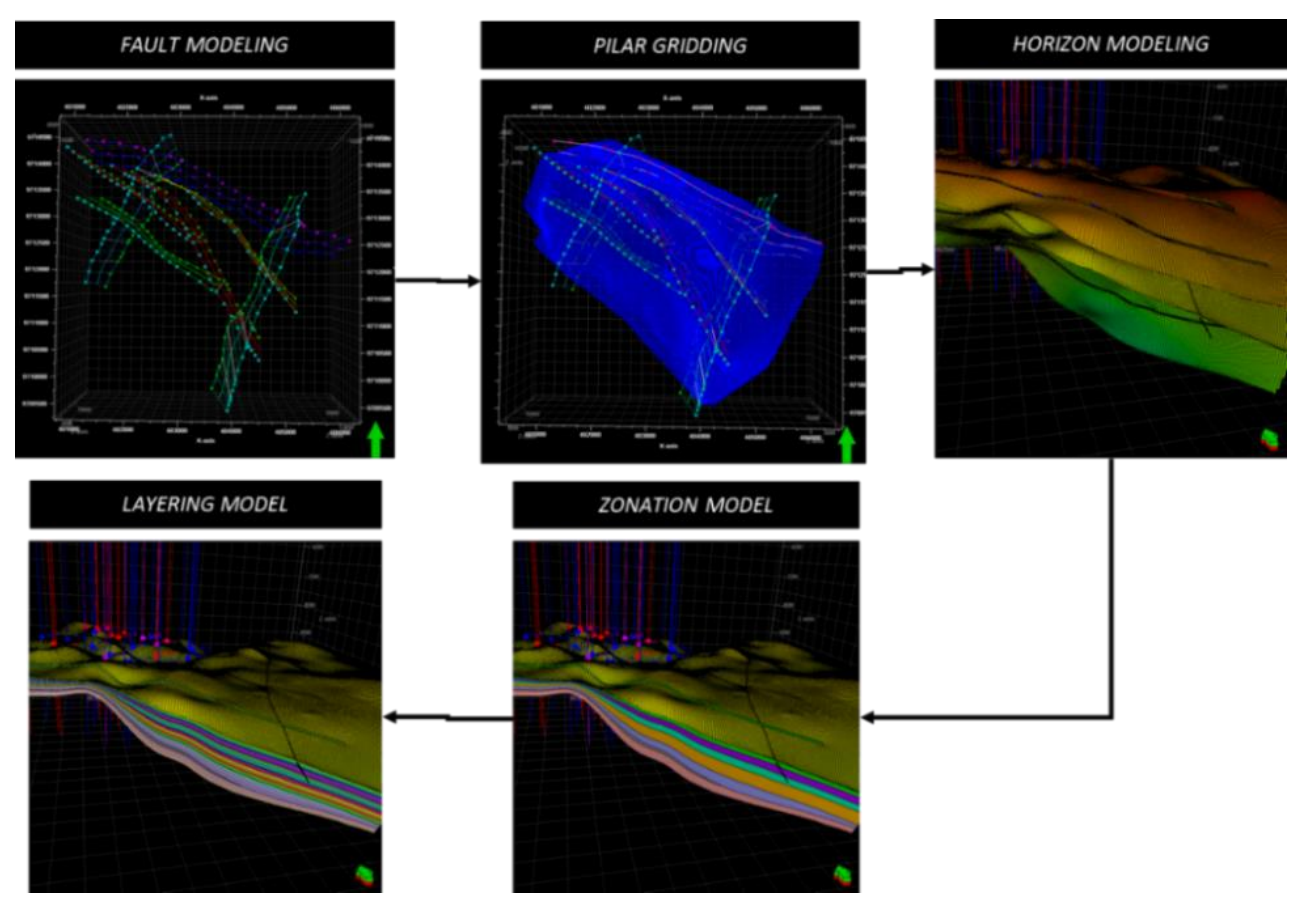

Gambar 7. Tahapan Pemodelan Struktural Yang Diawali Oleh Pemodelan Patahan, Pembuatan Pillar Gridding 3D, Horizon Modeling Hasil Dari Interpretasi Seismik, Pemodelan Zonasi Dan Pemodelan

$$
\text { Layer }
$$

Dalam tahapan pemodelan reservoir terdapat empat proses yaitu scale up well log, pemodelan litologi, pemodelan porositas, dan pemodelan saturasi air. Proses scale up well log dilakukan untuk perataan nilai log sumuran secara vertical di setiap sel dengan cara memasukkan data hasil analisis sumuran ke dalam model 3D grid. Validasi hasil scale up well logs dilakukan dengan melihat perbedaan antara histogram data log dengan hasil scale up.
Proses pemodelan Litologi dilakukan dengan menggunakan arah lingkungan pengendapan, menggunakan metode penyebaran Sequential Indicator Simulation. Analisis variogram pada data analisis juga digunakan untuk menyebarkan data pada jarak tertentu agar tidak ada perubahan nilai dengan orientasi sumbu major, minor variogram (Gambar 8). 


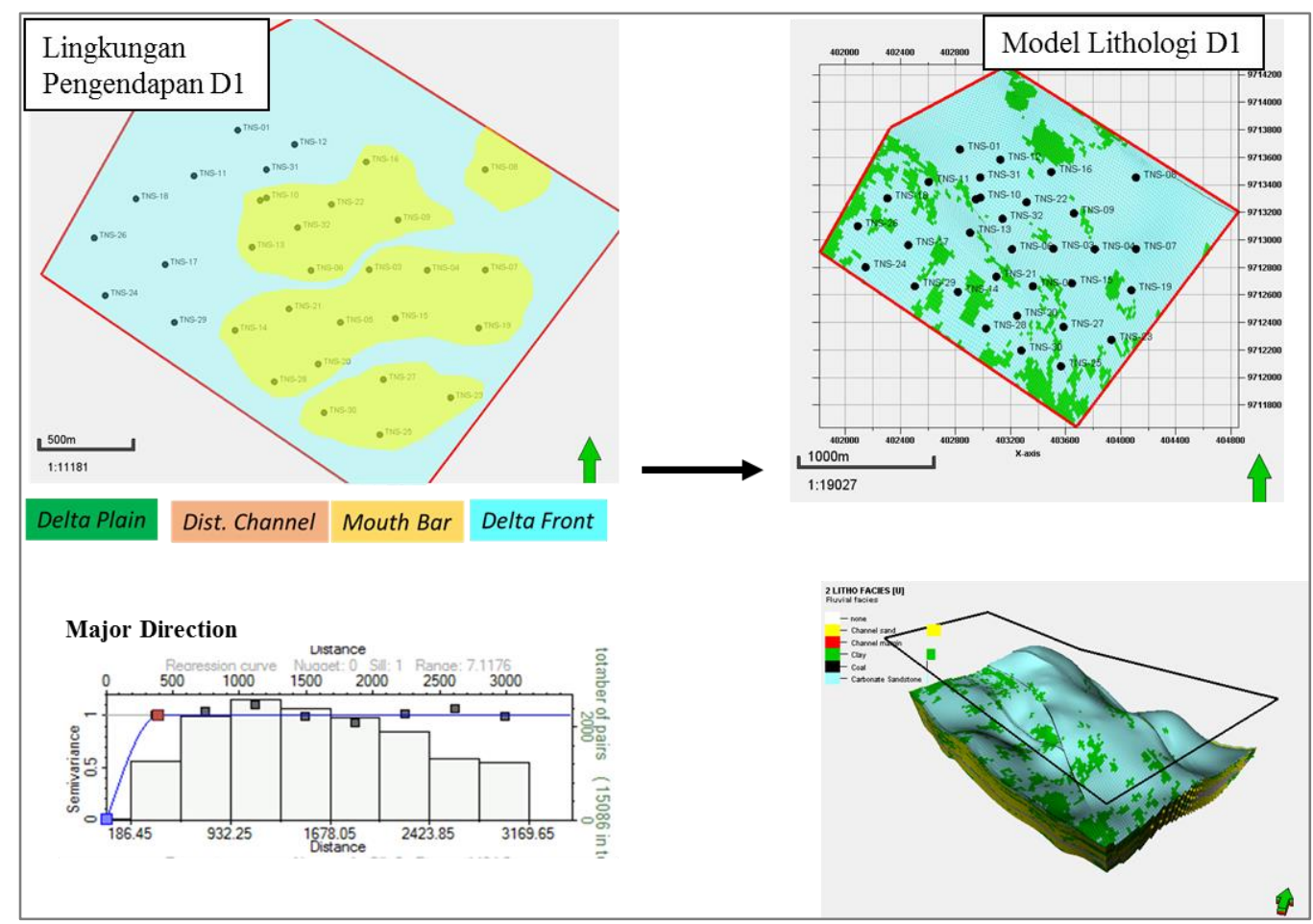

Gambar 8. Peta Lingkungan Pengendapan dan Analisis Variogram Digunakan Sebagai Arah Penyebaran Model Litologi dengan Metode Sequential Indicator Simulation

Pemodelan properti reservoir berhubungan erat dengan perhitungan OOIP. Log porositas dan $\log$ SW yang telah di scale up menjadi input dasar dalam pemodelan reservoir. Analisis variogram pada data analisis juga digunakan untuk menyebarkan data properti. Proses pemodelan porositas dikontrol oleh model litologi dan pemodelan $S W$ dikontrol oleh model porositas. (Gambar 9 dan Gambar 10). Penyebaran properti menggunakan metode penyebaran Sequential Gaussian Simulation. 


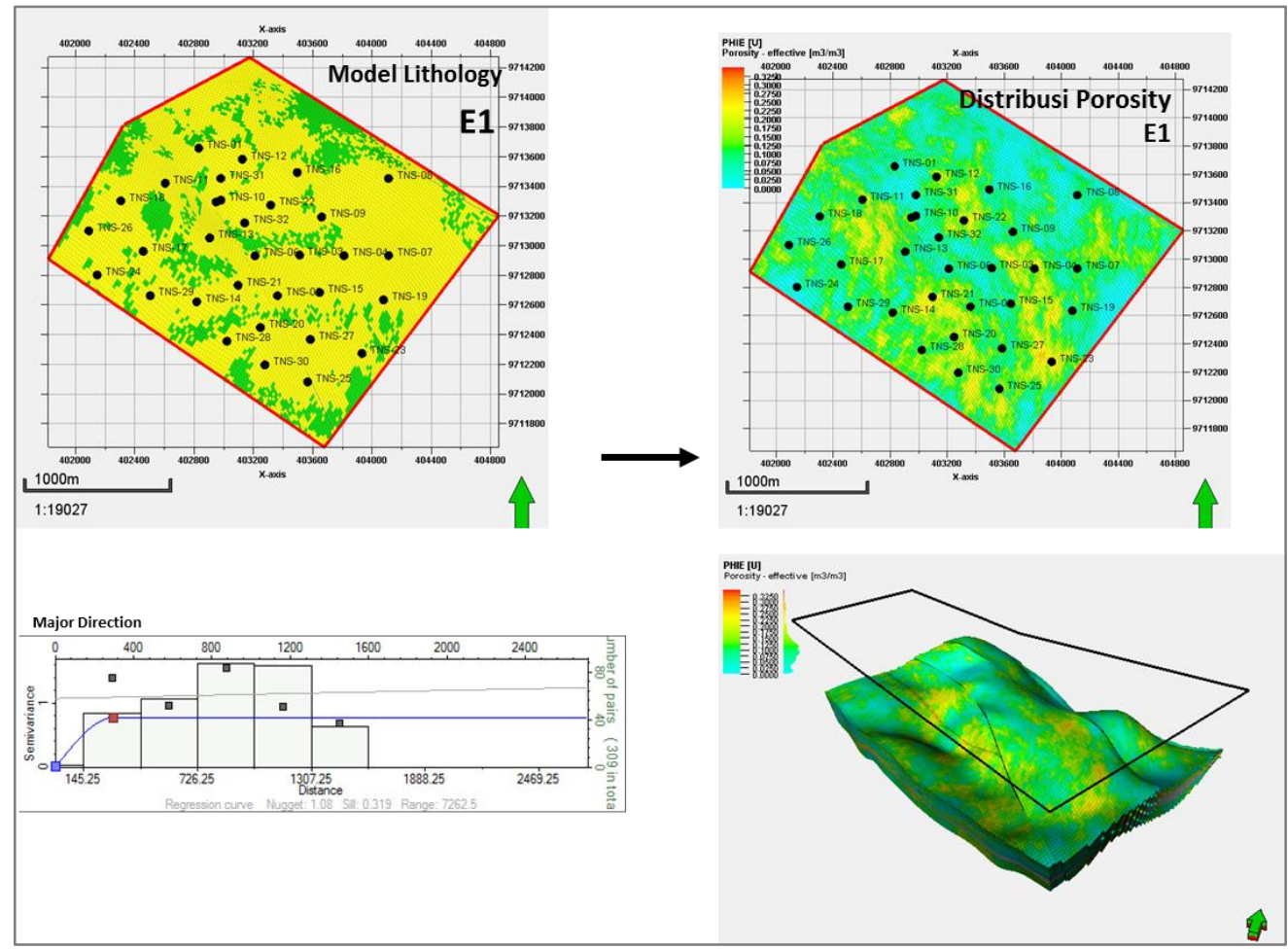

Gambar 9. Penyebaran Properti Porositas yang Dikontrol oleh Model Litologi dan Variogram dengan Menggunakan Metode Penyebaran Sequential Gaussian Simulation

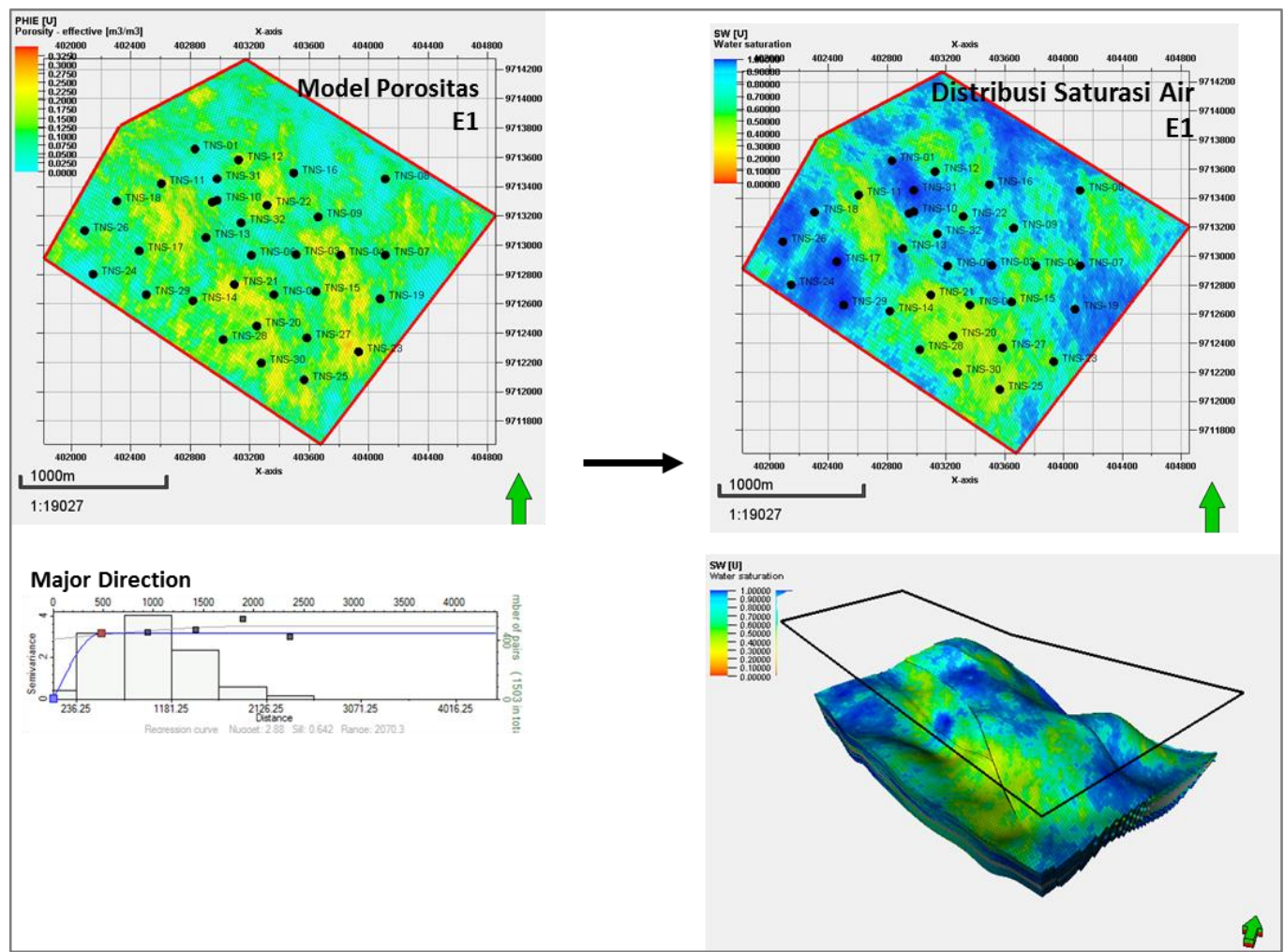

Gambar 10. Penyebaran Properti SW yang Dikontrol oleh Model Porositas Dan Variogram dengan Menggunakan Metode Penyebaran Sequential Gaussian Simulation 


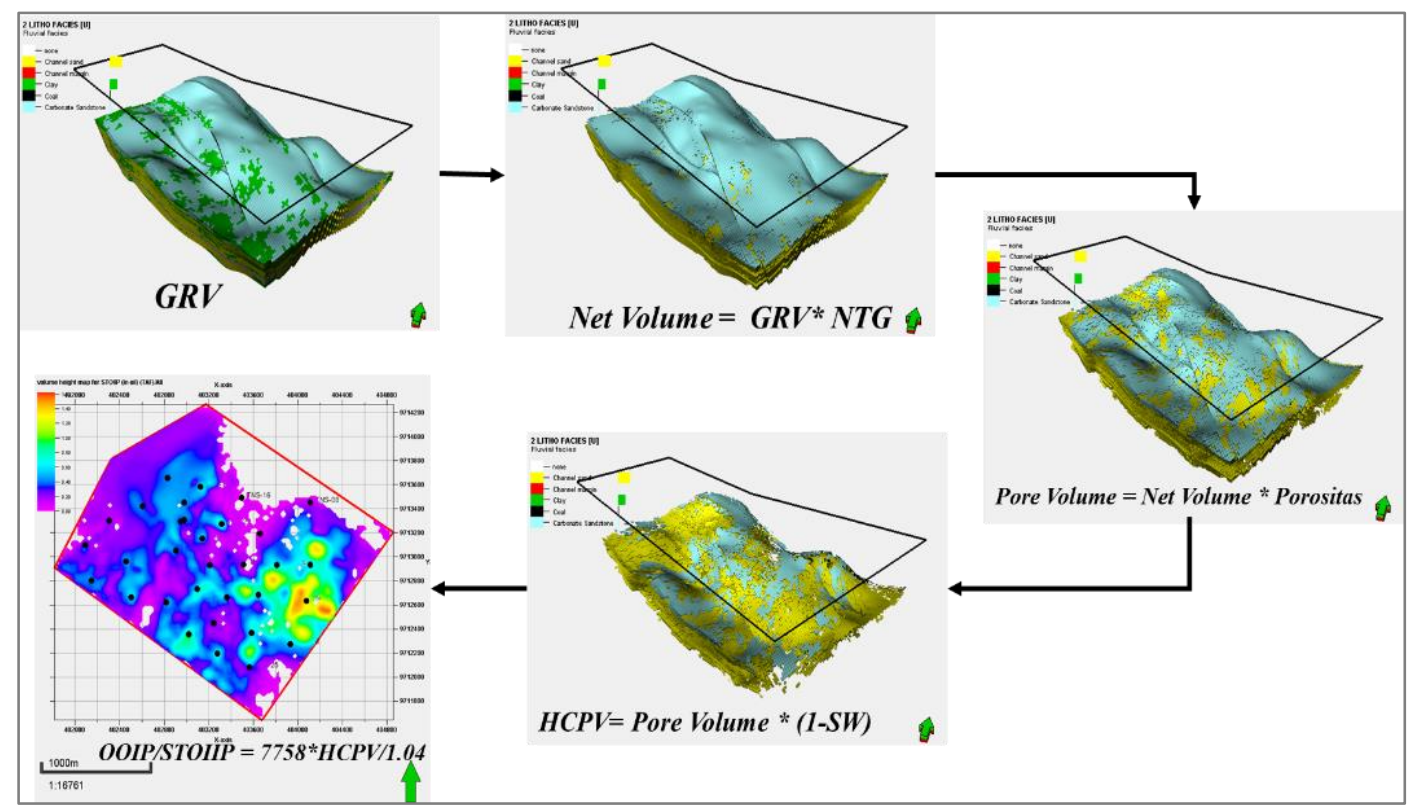

Gambar 11. Proses Perhitungan Hidrokarbon, Terlihat Volume Hidrokarbon Relatif Terakumulasi di Bagian Timur Daerah Penelitian

Hasil dari pemodelan dan distribusi property dapat digunakan untuk menentukan Terlihat volume hidrokarbon relatif terakumulasi di bagian timur daerah penelitian yan dipengaruhi oleh lingkungan pengendapan reservoir sehingga terjadinya perbedaan geometri dan properti reservoir ditunjukkan Gambar 11. Total OOIP lapangan ini sebesar 8,387 MSTB dengan potensi terbesar pada lapisan E2 2,340 MSTB terlihat pada Tabel 1.

Tabel 1. Perhitungan OOIP Formasi Talang Akar di Lapangan Sungai Lilin

\begin{tabular}{|l|l|l|l|l|l|}
\hline \multirow{2}{*}{ ZONE } & Bulk volume & Por & Swi & Boi & OOIP \\
\cline { 2 - 6 } & Acreft $)$ & $(\%)$ & $(\%)$ & bbl/STB & MSTB \\
\hline D1 & 1225.7 & 0.15 & 0.64 & 1.04 & 473 \\
\hline D2 & 1939.5 & 0.15 & 0.59 & 1.04 & 902 \\
\hline E1 & 3265.3 & 0.15 & 0.57 & 1.04 & 1,548 \\
\hline E2 & 2607.2 & 0.23 & 0.48 & 1.04 & 2,340 \\
\hline F & 2708.6 & 0.20 & 0.52 & 1.04 & 1,917 \\
\hline H & 2862.8 & 0.13 & 0.57 & 1.04 & 1,208 \\
\hline \multicolumn{5}{|l|}{ TOTAL } & \\
\hline
\end{tabular}




\section{Kesimpulan}

1. Analisis data log membagi reservoir litologi batupasir Formasi Talang Akar menjadi tujuh lapisan, yaitu D1, D2, E1, E2 , F, G, dan H tetapi hanya enam lapisan yang dilakukan penelitian karena lapisan $\mathrm{G}$ merupakan lapisan batubara.

2. Terdapat tiga dominan tipe log yaitu funnel shape, serrated shape dan bell shape yang menunjukkan daerah ini diendapkan pada di lingkungan distribution channel, delta plain, mouth bar, dan delta front.

3. Didapatkan nilai cut-off $\mathrm{Vcl}$ sebesar 0.4, porositas 0.1 dan $S W 0.7$.

4. Pemodelan reservoir diawali dengan melakukan distribusi litologi yang dikontrol oleh lingkungan pengendapan, kemudian properti hasil analisis petrofisik didistribusikan pada model geologi, menghasilkan pemodelan porositas dan pemodelan saturasi air.

5. Hasil perhitungan OOIP dengan menggunakan metode volumetrik pada Formasi Talang Akar di Lapangan Tanisha sebesar 8,387 MSTB dengan potensi terbesar pada lapisan E2 2,340 MSTB.

\section{Daftar Pustaka}

Argakoesoemah, R.M.I., dan Kamal. A., 2004. Ancient Talang Akar Deepwater Sediments In South Sumatra Basin. A New Exploration Play, IPA 2006 - IPA-AAPG Deepwater and frontier Symposium 2004

Bohling, G. 2005. Introduction to Geostatistics and Variogram Analysis. Kansas, hal. 2.

Harsono, A, 1997. Evaluasi Formation dan Aplikasi Log, Schlumberger Oilfield Services, Jakarta, hal 1.
Honh, M.E, 1999. Geostatic and Petroleum Geology-Second Edition, Kluwer Academic Publisher, Inggris, hal 2

Kalan, T., Maxwell, R.J., dan Calvert, .J.H,1984. Ramba And Tanjung Laban Oil Discoveries Corridor Block, South Sumatra, IPA 2006$13^{\text {th }}$ Annual Convention Proceeding

Partowidagdo, W, 2002. Manajemen dan Ekonomi Minyak dan Gas Bumi.

Purwanto, T., Isnaniawaghani, V., Mulyana, B., Widianto, E., 2015. Penentuan Posisi Marker Sekuen Stratigrafi Sebagai Dasar Pengikat Korelasi Lithostratigrfi Di Daerah Limau Cekungan Sumatra Selatan, Seminar Nasional Ke-II Fakultas Teknik Geologi Universitas Padjajaran

Schlumberger,2010.Petrel 2010.1 Full Manual. Schlumberger.

Selley, R.C, 1998. Elements of Petroleum Geology, Second Edition. USA: Academic Press, hal 240.

Sembodo, H., dan Nugrahanti, A, 2012. Penilaian Formasi II, Universitas Trisakti, Jakarta, hal. 46.

Tamtomo, B., Yuswar, I., Widianto, E., 1997. Transgressive Talang Akar Sands Of The Kuang Area, South Sumatra Basin: Origin, Distribution And Implication For Exploration Play Concept, IPA-Proseedings of The Petroleum System of SE Asia and Australasia Conference

Zakrevsky, K.E., 2011. Geological 3D modelling. European Association Geoscientist \& Engineers Publication, Belanda 